\title{
LXXXVIII. An examination of the green garnet of Sala
}

\section{B.G. Bredberg}

To cite this article: B.G. Bredberg (1823) LXXXVIII. An examination of the green garnet of Sala, Philosophical Magazine Series 1, 62:308, 423-425, DOI: 10.1080/14786442308644441

To link to this article: http://dx.doi.org/10.1080/14786442308644441

曲 Published online: 29 Jul 2009.

Submit your article to this journal ๘

Џ Article views: 2

Q View related articles $\sqsubset$ 
The difficulty with regard to fluoboric gas consists, probably, in its affinity for sulphuric acid, which, as Dr. Dary has shown, is so great as to raise the sulphuric acid with it in vapour. The experiments will however be continued on these and other gases, in the hopes that some of them, at least, will ultimately condense.

\section{An Examination of the green Gamet of Sala. By B. G. BredberG.*}

THE garnet of Sala, according to Haüy's crystallographical nomenclature, is Grenat trapezoidal, since it is bounded by 24 trapeziums, which are perceptibly striated parallel to the greater diagonal. The crystals are of a brownish yellow, sometimes of a yellowish green colour. Their surface has a resinous lustre; fracture uneven; lustre of the fracture dull; in thin splinters transparent; sometimes the crystals are semi. transparent throughout. They occur in a matrix of common limestone with crystals of calcareous spar, galena, and blende. At present this garnet is only met with in collections, since it has not been found for a long time in the mine itself. The specific gravity of a regular crystal was $3 \cdot 746$. Its result before the blowpipe is described in Berzelius's treatise on the application of that instrument as translated (into German) by H. Rose, p. 259.t The experiments with the blowpipe there mentioned, were undertaken with that species of garnet which is the subject of the analysis No. 2; that which was made use of for analysis No. 1 gave, on trying it before the blowpipe, a perfectly similar result. The analyses were made in the laboratory of Prof. Berzelius, where I had a favourable opportunity of acquiring the most preferable analytical method.

For the analysis No. 1 regular crystals were employed of a beautiful specimen, which, with several others, was found in the old mine by M. Pihl, captain of the mines, in the year 1780 .

In No. 2, intended as a correcting anaiysis, crystals from the collection of Prof. Berzelius were made use of. The

* Originally published in the Trans. Roy. Acad. Stockh., but above from a translation in Schweigger and Meinecke's Journal, N. R., band viii. p. 11.

+ In Mr. Children's valuable translation of this work into our own language the results obtained by subjecting this mineral to the agency of the blowpipe are thus described, at p. ๑82. "Fuses (without addition), with strong intumescence, into a black brilliant glass. With borax fuses slowly and difficuitly into a glass coloured by iron. With salt of phosphorus decomposes slowly, and leaves a silica skeleton. The tint from iron disappears on cooling. With sola decomposes and intumesces, but afterwards fuses into a black brilliant globule. On platina foil exhibits traces of manganese."-EDir.

specimen 
specimen belonged to such as were found at a later period in the same part of the mine, in 1800 , by the mining-master M. Billow. There was no apparent ground to expect so great a difference as the analyses afterwards indicated in the composition of two specimens so similar in their appearance, their conduct before the blowpipe, and their form, and which had been found in the same mine.

\section{Analyses.}

In No. 1, the levigated powder was decomposed by concentrated muriatic acid, in which it was boiled for three days consecutively, after which the silica remained behind in gelatinous lumps. In No. 2, on the contrary, the mineral was treated with carbonate of potassa, and exposed to a red-heat in a platinum crucible. In other respects both were proceeded with in the following manner:

The acid fluid, after the separation of the silica, was precipitated by a trifling excess of caustic ammonia; the precipitate, after the lapse of some hours, was placed on a filter, and washed with boiling water, and then boiled for an hour with caustic potassa. The alkaline solution of alumina was supersaturated with muriatic acid, and the earth precipitated by carbonate of ammonia, washed and exposed to a red-heat. The oxide of iron left undissolved by the caustic lixivium, was dissolved in muriatic acid; the solution mixed with a little nitrous acid was made boiling hot, then neutralised with caustic ammonia, and precipitated with succinate of ammonia. The succinate of iron was converted to a red oxide in an open platinum crucible. The fluid obtained after the first precipitation by caustic ammonia was diluted, warmed, and precipitated with a solution of oxalate of potassa; the precipitate collected on the filter was washed, and exposed to a red-heat in a platinum crucible. In determining the quantity of lime, I tried it, for the sake of certainty, with carbonate of ammonia, and when, after two or three such trials, no alteration in weight took place, the proportion of lime was calculated from the weight of carbonate of lime thus obtained. The solutions, after the separation of the lime and iron, were put together, mixed with a few drops of muriatic acid, in order to keep the difficultly soluble oxalate of magnesia in a state of solution, and afterwards mixed, in a boiling state, with a sufficient quantity of carbonate of potassa. After evaporating them to dryness, and redissolving in boiling water, they yielded magnesia. In No. 1, a trace of manganese was indicated by this process. In No. 2, on the contrary, the earth was scarcely discoloured after ignition. 
Mr. Seaward on Sispersion Chain Bridges.

The following were the results of the analyses:

\begin{tabular}{|c|c|c|c|}
\hline & $\begin{array}{l}\text { No. } 1 . \\
36.62\end{array}$ & . & $\begin{array}{l}\text { No. } 2 . \\
36.73\end{array}$ \\
\hline Alumina .............. & $7 \cdot 53$ & $\ldots$ & $2 \cdot 78$ \\
\hline Oxide of iron $\ldots \ldots$ & $22 \cdot 18$ & $\ldots$ & $25 \cdot 83$ \\
\hline Lime................ & $13 \cdot 80$ & $\ldots$ & $21 \cdot 79$ \\
\hline Magnesia ............ & 1.95 & $\cdots$ & $12 \cdot 4 \cdot 4$ \\
\hline & .08 & & \\
\hline
\end{tabular}

The amount of oxygen, calculating from these results, is as follows :

\begin{tabular}{|c|c|c|c|}
\hline In the silica.......... & $\begin{array}{l}\text { No. } 1 . \\
18 \cdot 42\end{array}$ & & $\begin{array}{l}\text { No. } 2 . \\
18 \cdot 47\end{array}$ \\
\hline In the alumina...... & $3 \cdot 51\}$ & $10 \cdot 01$ & $1 \cdot 307$ \\
\hline In the oxide of iron & $6.80\}$ & -1031 & $7 \cdot 62\}$ \\
\hline $\begin{array}{l}\text { In the lime.......... } \\
\text { In the magnesia... }\end{array}$ & $8 \cdot 93$ & $9 \cdot 68$ & $5 \cdot 12\}$ \\
\hline n the magnesia... & 0.75 & & $4.81 J$ \\
\hline
\end{tabular}

The excess yielded by the analysis No. 1 is probably owing to a portion of protoxide of iron which the fossil appears to have contained together with the peroxide. The calculation from the proportions of oxygen gives reason for this supposition.

The mineralogical formula of these garnets of Sala is

$$
\underset{\mathrm{M}}{\mathrm{C}}\} \mathrm{S}+\underset{\mathrm{F}}{\mathrm{A}}\} \mathrm{s} \text {. }
$$

LXXXIX. Observations on Suspension Chain Bridges; with an improved Method of forming the supporting Chains or Rods: accompanied with a Drawing. By Mr. J. Seaward.

\section{To the Editors of the Philosophical Magazine and Journal.}

BEING some time back engaged in examining the Plans of a Suspension Bridge proposed to be erected in a distant part of England, I was forcibly struck with what appeared to me to be a great sacrifice of strength in the mode which is usually adopted in forming the suspending chains of such structures.

Under this impression, I was induced to offer a plan for a suspension bridge on quite a different principle; the peculiar recommendation of which is to ensure much greater strength and stability from a given quantity of materials, than what can be obtained according to the present plan. My design was shown to several scientific gentlemen, but a want of confidence, I believe, prevented it from being adopted. My views of the subject are however unchanged, and I am satisfied that,

Vol. 62. No. 308. Dec. $1823 . \quad 3 \mathrm{H}$ wre 